\title{
Níveis séricos de enzimas hepáticas em poedeiras comerciais no pré-pico e pico de produção de ovos
}

\author{
Serum Levels of Liver Enzymes in Laying Hens before and during the Peak of Egg Production
}

\author{
Fernanda Medeiros Gonçalves', Érico de Mello Ribeiro², Paula Montagner ${ }^{2,5}$, Mateus Silveira Lopes ${ }^{2,5}$, \\ Marcos Antonio Anciuti ${ }^{1,3}$, Fabiane Pereira Gentilini ${ }^{1}$, Francisco Augusto Bukert Del Pino ${ }^{1,4}$ \& Marcio \\ Nunes Corrêa ${ }^{2,5}$
}

\begin{abstract}
Background: The biochemistry evaluation of liver enzymes gives evidences about metabolic disorders caused by diseases or nutritional deficiency that influence the hepatic activity. The biochemical profile is usually used as a support for diagnosis of hepatic diseases in pets, however the same evaluation it's not used in cattle. At the same time, there is a few results and benchmarks for commercial poultry biochemical profile, without a consensus between layer activity, breeder lines, period, age, region, nutrition, and other factors that can interfere in data assurance. AST enzyme is considered a responsive marker in liver disorder in chicken, even if is a nonspecific parameter. GGT can indicate cholestasis and biliary ducts proliferation in chicken liver. The aim is compare the levels of aspartate aminotransferase (AST) e gammaglutamyl transferase (GGT), before and during the pick of egg production.

Materials, Methods \& Results: Thirty-five Hisex Brown laying hens with 16 weeks of age were used for the research. The birds were distributed in a total of seven birds per cage. The hens received the same feed during the experimental period, varying the nutrition levels according layer stage. The experimental design was in random blocks and the animals were in same environment conditions. The light program used was $16 \mathrm{~h}$ of artificial lighting per day, with a dark break of eight hours. Three milliliters per bird were collected before the pick ( 23 weeks) and during the pick of egg production ( 31 weeks), always in the morning period with a previous fasting. The blood was collected in left wing vein in vacuum tubes. The biochemistry analyses were made with specifics kits for AST and GGT determination. Two analyses of each parameter were made per blood sample in a total of 70 analyses. Data were submitted to variance analyses and the averages were compared in Tukey in a significance level of $1 \%$.

Discussion: The levels of AST and GGT in the pre pick of egg production were significantly higher $(P<0,0001)$ than in the pick of production. During this period (30 to 56 weeks of age) the egg production reaches values upward $90 \%$, corresponding to a stage of higher demand for nutrients, mainly amino acids, to attend maximum potential of hen production. However, feed increase is performed in pre pick of production to stimulate layers to reaches the pick of egg production. Thus, liver are extremely forced to process with efficiency the diets ingredients, causing liver cells lyses putting out their contents, increasing AST and GGT levels. In physiological conditions, both AST and GGT enzymes are found in lower levels in blood and higher concentrations inside liver cells. Therefore, a substantial increase of this liver enzymes are associated with tissue disturbance, increase membrane permeability and liver enzymes escape to blood serum. Based on the available data, it was concluded that increasing feed in the pre pick period causes a higher overload in liver of commercial laying hens, increasing serum levels of AST and GGT enzymes. It is recommended other researches with the main point of set up reference values for layers biochemical profile in different stages of egg production and for different breeders.
\end{abstract}

Keywords: aspartate aminotransferase, gammaglutamyl transferase, metabolic profile.

Descritores: aspartato aminotransferase, gama-glutamiltransferase, perfil metabólico.

${ }^{1}$ Programa de Pós-graduação em Zootecnia, Universidade Federal de Pelotas (UFPel), Campus Universitário, s/n, CEP 96015-360 Pelotas, RS, Brasil. ${ }^{2}$ Faculdade de Veterinária, UFPel. ${ }^{3}$ Instituto Federal Sul-rio-grandense (IF-Sul), Campus CAVG, Pelotas. ${ }^{4}$ Laboratório de Bioquímica Clínica, UFPel. ${ }^{5}$ Núcleo de Pesquisa, Ensino e Extensão em Pecuária (NUPEEC), UFPel. CORRESPONDÊNCIA: F.M. Gonçalves [fmedeiros_fv@ufpel.edu.br - Fax +55 (53) 3275 7274]. 


\section{INTRODUÇÃO}

Análises da bioquímica sanguínea são utilizadas para auxílio no diagnóstico e caracterização de doenças em animais, mas pouco utilizadas para espécies aviárias, ainda que representem uma ferramenta útil no diagnóstico de distúrbios metabólicos nesses animais [1].

Valores de referência de perfil bioquímico em aves comerciais são escassos na literatura mundial, não havendo padronização quanto a atividade produtiva, linhagem, período, região, nutrição, entre outros fatores, o que dificulta o uso destes dados [2].

O fígado é o principal órgão metabólico do organismo animal, destacando-se, dentre suas funções, a síntese de proteínas plasmáticas, secreção da bile e desintoxicação de substâncias estranhas [11]. As enzimas hepáticas representam marcadores confiáveis para a detecção de transtornos metabólicos, indicando alteração neste órgão. A enzima AST é considerada um marcador sensível de distúrbio hepatocelular em aves, ainda que seja inespecífica [14]. Já a GGT, indica colestases e proliferação de ductos biliares no fígado de aves [5]. Devido às variações decorrentes de região, nutrição, estado fisiológico e resposta individual dos animais, a caracterização dos parâmetros fisiológicos permitirá estabelecer valores de referência para a espécie [13].

Produtores de ovos comerciais frequentemente aumentam ou mantém altas quantidades de ração visando um aumento de 0,1 a $0,5 \%$ no pico de produção de ovos, obtendo aves pesadas, não competentes em metabolizar o excesso de energia fornecida [12].

Diante do exposto, objetivou-se comparar os níveis de AST e GGT nas fases de pré-pico e pico de produção de ovos em poedeiras comerciais.

\section{MATERIAIS E MÉTODOS}

\section{Instalações e Animais}

O estudo foi conduzido no aviário experimental do Conjunto Agrotécnico "Visconde da Graça" (CAVG), pertencente à Universidade Federal de Pelotas (UFPel), no período de 28 de janeiro a 15 de fevereiro de 2008. Foram utilizadas 35 poedeiras semipesadas da linhagem Hisex brown ${ }^{1}$, criadas e recriadas em aviários dark house e transferidas com 16 semanas de idade, com peso entre 1100 a $1200 \mathrm{~g}$, para o aviário experimental em sistema de baterias de gaiolas de postura. Na transferência, foram alojados grupos de sete aves por gaiola, com disponibilida- de de água em bebedouros tipo nipple ${ }^{2}$ e fornecimento de ração em comedouros tipo calha.

\section{Manejo e Delineamento Experimental}

A quantidade de ração fornecida apartir das 16 semanas de idade (período pré pico de produção) foi de $83 \mathrm{~g} / \mathrm{ave} / \mathrm{dia}$, aumentando-se três gramas por semana até atingir 109 g/ave/dia nas 31 semanas de idade (pico de produção). Todas as aves receberam o mesmo manejo diário e a mesma dieta durante todas as fases, onde apenas os valores nutricionais variaram conforme o período de vida dos animais. O programa de luz utilizado foi de $16 \mathrm{~h}$ diárias de luz artificial, com intervalo de $8 \mathrm{~h}$ de escuro. $\mathrm{O}$ delineamento experimental foi em blocos casualizados, com as aves sob as mesmas condições ambientais.

\section{Coletas de Sangue e Análise do Perfil Metabólico}

A coleta de sangue foi realizada no período da manhã, com jejum prévio de uma hora, através de venopunção da veia braquial esquerda. Foram coletados $3 \mathrm{~mL}$ de sangue de cada ave em tubos à vácuo ${ }^{3}$, sem anticoagulante, para a obtenção do soro sanguíneo, conforme indicado pelo laboratório dos kits reagentes ${ }^{4}$ utilizados no experimento. As coletas foram realizadas nas 23 semanas de idade, em fase de pré-pico de produção, e com 31 semanas de idade, onde a produção de ovos atingia 92\%, caracterizando a fase de maior produtividade na vida das aves (fase de pico de produção). As análises bioquímicas foram realizadas no laboratório de bioquímica clínica do Departamento de Bioquímica da UFPel, através de kits específicos para determinação de aspartato-aminotransferase (AST) e gamaglutamiltransferase (GGT). Duas análises de cada parâmetro foram realizadas para cada amostra de sangue, totalizando 70 análises de AST e 70 análises de GGT. Os dados obtidos foram submetidos à ANOVA e as médias comparadas pelo teste de Tukey ao nível de $1 \%$.

\section{RESULTADOS}

De acordo com os resultados apresentados (Tabela 1 e Figura 1), os níveis de AST e GGT no período de pré-pico de produção, foram significativamente superiores aos níveis no pico de produção de ovos.

\section{DISCUSSÃO}

Andreasen et al. [1], encontraram valores de AST e GGT em poedeiras comerciais com 57 semanas de idade (pós-pico de produção), de uma outra linha- 
Tabela 1. Níveis de AST e GGT em U/L de soro sanguíneo em poedeiras comerciais no pré-pico (23 semanas de idade) e durante o pico (31 semanas de idade ) de produção de ovos obtidos no aviário experimental (CAVG) - Universidade Federal de Pelotas (UFPel), durante período de 28 de janeiro a 15 de fevereiro de 2008.

\begin{tabular}{ccc}
\hline Fase produtiva & AST (U/L) & GGT (U/L) \\
\hline $\begin{array}{c}\text { Pré-pico de produção } \\
\text { de ovos }\end{array}$ & $89,77^{\mathrm{a}}$ & $35,02^{\mathrm{a}}$ \\
$\begin{array}{c}\text { Pico de produção de } \\
\text { ovos }\end{array}$ & $57,29 \mathrm{~b}$ & $17,37 \mathrm{~b}$ \\
Valor de P & $<0,0001$ & $<0,0001$ \\
$\mathrm{CV} \%$ & 23,81 & 0,33 \\
\hline $\mathbf{R} 2$ & 0,46 \\
$\mathbf{8 0}$ \\
$\mathbf{6 0}$ \\
$\mathbf{4 0}$ \\
$\mathbf{2 0}$ \\
$\mathbf{0}$
\end{tabular}

Figura 1. Níveis de AST e GGT em U/L de soro sanguíneo em poedeiras comerciais no pré-pico ( 23 semanas de idade) e durante o pico de produção de ovos (31 semanas de idade). Ambas enzimas apresentam-se em concentrações elevadas em pré-pico de produção de ovos, indicando espoliação do órgão neste período que antecede a fase de maior produção.

${ }^{\text {ab } M e d i d a s ~ n a ~ m e s m a ~ c o l u n a ~ c o m ~ l e t r a s ~ d i s t i n t a s ~ d i f e r e m ~ p e l o ~ t e s t e ~ T u r k e y ~}$ $(P<0,0001)$.

gem comercial, próximos aos obtidos neste estudo.

Durante o pico de postura (de 30 a 56 semanas de idade), a produção de ovos atinge percentuais superiores a $90 \%$, sendo, provavelmente, o período em que a demanda de nutrientes se torna mais elevada, principalmente o nível de aminoácidos, para atender o máximo potencial de produção das aves [7]. Entretanto, o incremento de ração é realizado no período pré pico de produção para estimular as aves a atingirem tal fase. Desta maneira, o sistema hepático é altamente exigido para metabolização de parte dos nutrientes provenientes da dieta, ocasionando lise das células hepáticas e, consequentemente, o extravasamento de seus componentes intracelulares, aumentando os níveis de AST e GGT circulantes. A AST está presente em muitos tecidos, sendo um indicativo de danos em tecidos moles, especialmente tecidos cardíacos e hepáticos [10].

Em condições fisiológicas, tanto a enzima AST quanto a enzima GGT são encontradas em baixas concentrações no plasma sanguíneo e em altas quantidades no interior dos hepatócitos. Mais especificamente, a AST encontra-se presente no citossol ou nas mitocôndrias da célula hepática, e a GGT encontra-se em sítios específicos da membrana plasmática [3]. Desta maneira, um aumento da atividade sérica de tais enzimas está correlacionado com alterações teciduais, com aumento de permeabilidade das membranas plasmáticas e escape das enzimas para o soro [8]. Segundo Gonzáles et al. [6], quando interpretados 
adequadamente, os valores bioquímicos do plasma fornecem importantes informações em relação ao estado clínico de um animal, ao balanço nutricional, a situações deficitárias, a monitorações de tratamentos e a prognósticos.

\section{CONCLUSÃO}

Conclui-se que o incremento de ração no período pré-pico promove maior sobrecarga hepática das aves de postura, elevando os níveis séricos das enzimas AST e GGT.
Recomendam-se novos estudos para o estabelecimento de valores de referência do perfil bioquímico de poedeiras comerciais em diferentes fases da vida produtiva e para as diferentes linhagens.

\section{NOTAS INFORMATIVAS}

IInteraves, São Paulo, SP, Brasil.

${ }^{2}$ Agromarau, Marau, RS, Brasil.

${ }^{3}$ BD Vacuntainer ${ }^{\oplus}$, Franklin Lakes, USA

${ }^{4}$ Labtest Diagnóstica ${ }^{\circledR}$ S/A, Lagoa Santa, MG, Brasil

\section{REFERÊNCIAS}

1 Andreasen J.R., Andreasen C.B., Sonn A.B. \& Robeson D.C. 1996. The effects of haemolysis on serum chemistry measurements in poultry. Avian Pathology. 25(3): 519-536.

2 Borsa A., Kohayagawa A., Boretti L.P., Saito M.E. \& Kuibida K. 2006. Níveis séricos de enzimas de função hepática em frangos de corte de criação industrial clinicamente saudáveis. Arquivos Brasileiro de Medicina Veterinária e Zootecnia. 58(4): 675-677.

3 Evans G.O. 2009. General Enzymology. In: Evans, G.O. (Ed). Animal Clinical Chemistry: a practical handbook for toxicologists and biomedical researchers. 2nd edn. Boca Raton: CRC Press, pp.17-36.

4 Franciscato C., Lopes S.T.A., Veiga A.P.M., Martins D.B., Emanuelli M.P. \& Oliveira L.S.S. 2006. Atividade sérica das enzimas AST, CK e GGT em cavalos Crioulos. Pesquisa Agropecuária Brasileira. 41(10): 1561-1565.

5 Gonzáles F.H.D. \& Silva S.C. 2006. In: Introdução à Bioquímica Clínica Veterinária. 2.ed. Porto Alegre: UFRGS Editora, 360 p.

6 Gonzáles F.H.D., Carvalho V., Möller V.A. \& Duarte F.R. 2001. Perfil bioquímico sangüíneo de cães e gatos na cidade de Porto Alegre, Rio Grande do Sul, Brasil. Arquivos da Faculdade de Veterinária UFRGS. 29(1): 1-6.

7 Jordão J., Silva J.H.V., Silva E.L., Ribeiro M.L.G., Costa F.G.P. \& Rodrigues P.B. 2006. Exigência de lisina para poedeiras semipesadas durante o pico de postura. Revista Brasileira de Zootecnia. 35(4): 1728-1734.

8 Kramer J.W. \& Hoffmann W.E. 1997. Clinical Enzymology. In: Kaneko J.J., Harvey J.W. \& Bruss M.L. (Eds). Clinical Biochemistry of Domestic Animals. 5th edn. London: Academic Press, pp.303-323.

9 Nelson D.L. \& Cox M.M. 2006. Princípios de Bioquímica. 4.ed. São Paulo: Sarvier Editora, 1202 p.

10 Raposo J.B., Fernandes C.G., Baialardi C. \& Driemeier D. 2004. Observações clínicas e bioquímicas em bovinos intoxicados experimentalmente por Myoporum laetum. Acta Scientiae Veterinarie. 32: 9-17.

11 Reece W.O. 2007. In: Reece W.O. Dukes: Fisiologia dos Animais Domésticos. 12.ed. Rio de Janeiro: Guanabara Koogan, pp.374-386.

12 Sakomura N.K., Santos A.L., Freitas E.R. \& Rabello C.V.B. 2004. Programas de Alimentação para Matrizes Pesadas após o Pico de Postura, com Base em Modelos para Predizer a Exigência Energética. Revista Brasileira de Zootecnia. 33(5): 1197-1208.

13 Santos E.O. 2006. Perfil bioquímico-hematológico em lhamas (Lama glama Linnaeus 1758) criadas em cativeiro no sul do Brasil: variações de gênero e época do ano. Acta Scientiae Veterinarie. 35(2): 281-282.

14 Schmidt E.M.S., Locatelli-Dittrich R., Santin E. \& Paulillo A.C. 2007. Patologia clínica em aves de produção - uma ferramenta para monitorar a sanidade avícola. Archives of Veterinary Science.12(3): 9-20.

15 Tennant B.C. 1997. Hepatic function. In: Kaneko J.J., Harvey J.W. \& Bruss M.L. (Eds). Clinical Biochemistry of Domestic Animals. 5th edn. London: Academic Press, pp.327-352. 